University of Nebraska - Lincoln

DigitalCommons@University of Nebraska - Lincoln

2006

\title{
Detection of Inclement Weather Conditions at a Signalized Intersection using a Video Image Processing Algorithm
}

\author{
Anuj Sharma \\ University of Nebraska - Lincoln, anujs@iastate.edu \\ Darcy M. Bullock \\ Purdue University, darcy@purdue.edu \\ Srinivas Peeta \\ Purdue University, peeta@purdue.edu \\ James V. Krogmeier \\ Purdue University, jvk@ecn.purdue.edu
}

Follow this and additional works at: https://digitalcommons.unl.edu/civilengfacpub

Part of the Civil Engineering Commons

Sharma, Anuj; Bullock, Darcy M.; Peeta, Srinivas; and Krogmeier, James V., "Detection of Inclement Weather Conditions at a Signalized Intersection using a Video Image Processing Algorithm" (2006). Civil Engineering Faculty Publications. 32.

https://digitalcommons.unl.edu/civilengfacpub/32

This Article is brought to you for free and open access by the Civil Engineering at DigitalCommons@University of Nebraska - Lincoln. It has been accepted for inclusion in Civil Engineering Faculty Publications by an authorized administrator of DigitalCommons@University of Nebraska - Lincoln. 


\title{
DETECTION OF INCLEMENT WEATHER CONDITIONS AT A SIGNALIZED INTERSECTION USING A VIDEO IMAGE PROCESSING ALGORITHM
}

\author{
Anuj Sharma ${ }^{l a}$, Darcy Bullock $^{b}$, Srinivas Peeta ${ }^{c}$, and James Krogmeier ${ }^{d}$ \\ ${ }^{a}$ Graduate Research Assistant; ${ }^{b}$ Professor; ${ }^{c}$ Professor; ${ }^{\mathrm{d}}$ Associate Professor \\ Purdue University
}

\begin{abstract}
Inclement weather conditions like snowfall adversely affect traffic flow characteristics, necessitating a change in parameters that define the operation of a signalized intersection. A weather-based timing plan selection is needed to maintain a desirable level of operational efficiency. Automatic implementation of weather-based timing at intersections requires accurate and timely detection of snowfall. This paper presents a snow detection algorithm that uses live video feed obtained from a video image vehicle detection system present at an intersection.
\end{abstract}

Index Terms - Inclement weather, traffic control, detectors.

\section{GLOSSARY}

This section defines for the transportation terminology used in this paper. These definitions are borrowed from Highway Capacity Manual [1], and ASC/3 traffic controller manual [2].

Saturation flow rate: The flow rate rate at which previously queued vehicles can traverse an intersection approach under prevailing conditions, assuming that the green signal is available at all times and no lost times are experienced. Typically expressed in vehicles per hour or vehicles per hour per lane;

Start-up lost time: The additional time, in seconds, consumed by the first few vehicles in a queue at a signalized intersection above and beyond the saturation headway, because of the need to react to the initiation of the green phase and to accelerate;

Free-flow speed: The theoretical speed of traffic, in miles per hour, when density is zero (that is, when no vehicles are present);

Cycle: A complete sequence of signal indications;
Phase: The part of the signal cycle allocated to any combination of traffic movements receiving the right-ofway simultaneously during one or more intervals;

Maximum Green: Maximum green time allowed for a single phase in the presence of an opposing call;

Minimum Green: Minimum green time that is provided before the phase can shift to another movement;

Phase Vehicle Extension (Preset gap, Passage time): When minimum green finishes timing, the green interval is allowed to extend for a length of time equal to phase vehicle extension on each vehicle actuation;

Gap Out: Termination of green phase when actual time gap between vehicles has exceeded phase vehicle extension.

Change interval: The yellow plus all-red interval that occurs between phases of a traffic signal to provide for clearance of the intersection before conflicting movements are released.

\section{INTRODUCTION}

Inclement weather conditions (like snowfall) adversely affect traffic flow characteristics, necessitating a change in parameters that define the operation of a signalized intersection. Figure 1 illustrates the change in traffic flow characteristics at an intersection under normal weather conditions versus when a recent snowfall has occurred. There is a parabolic relationship between density of flow and flow rate. Under normal circumstances, an actuated intersection is operated near capacity as shown in Figure 1. In the event of a snowfall, vehicles usually tend to move at slower speeds and maintain longer headways, resulting in a new relationship between density and flow. To maintain operational efficiency, the traffic signal timing plan parameters such as minimum green time, vehicle extension time, maximum green time and change intervals should be adjusted appropriately. Using a weather-based timing plan selection enhances both operational efficiency and safety.

\footnotetext{
${ }^{1}$ Address: Department of Civil Engineering, Purdue University. West Lafayette, IN-47907.

Email: sharma23@purdue.edu.

Tel: 765-494-2206

Fax: 765-496-7996
} 
For example, if the vehicle extension time is not increased in

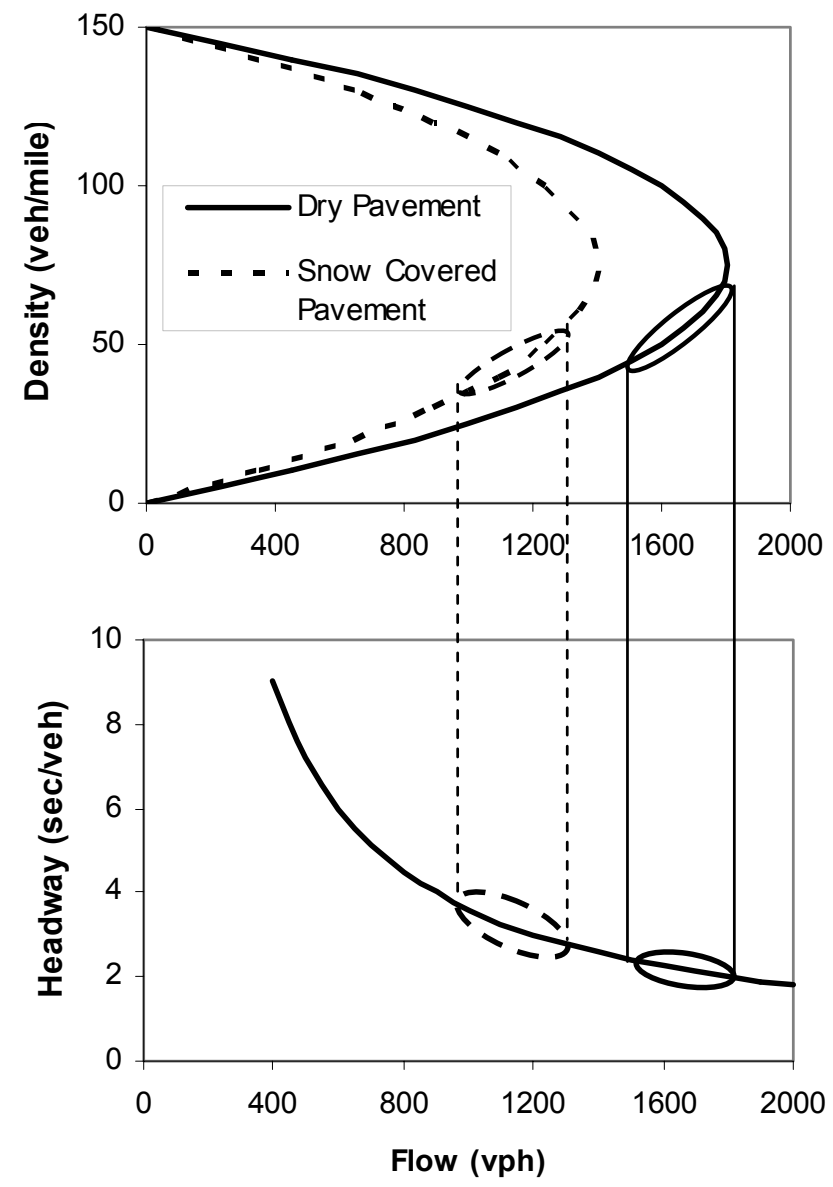

Figure 1 Illustrative comparison of traffic flow in normal and snowy conditions

the event of snowfall, the green phase will prematurely gap out. Premature gap out of green phase can subject drivers to the dangerous dilemma of either stopping the vehicle in a short distance or running the red light. If a driver decides to stop using a high deceleration rate, the vehicle might skid leading to unsafe conditions. Also, the change intervals need to be adjusted taking into consideration the reduced pavement friction and lower speeds.

Accurate and timely detection of snowfall at the intersection site is a challenging task. In recent years video image vehicle detection systems (VIVDS) have emerged as an alternative vehicle detection device. These systems detect vehicles using image processing and send the actuation to the traffic controller to make appropriate decisions. The same system can be used for snow detection.

The following section gives a brief overview of past research that evaluates the impact of inclement weather on traffic flow parameters.

\section{EFFECTS OF INCLEMENT WEATHER ON TRAFFIC PARAMETERS}

Past research $[3,4,5,6,7,8]$ addresses how inclement weather affects: saturation flows, pedestrian walking speeds, start-up lost time, change intervals.

Saturation flow decreases during inclement weather conditions due to more cautious driving. Drivers maintain larger headways, drive at slower speeds and have decreased desired acceleration rates. Table 1 compares the reduction in saturation flow reported from: Salt Lake City, Utah [3]; Fairbanks, Alaska [4]; Anchorage, Alaska [5]; and Minneapolis, Minnesota [7].

The change in travel speed due to severe weather affects the dilemma zone boundaries and can be critical in estimating the change interval (yellow and all-red duration) for the specific intersection. The FHWA [6] assessed the impact of inclement weather on speed. FHWA and found up to $42 \%$ speed reduction based on storm severity.

Inclement weather conditions also affect the start-up lost time used to calculate minimum green times. Martin et al. [3] reported an increase of $23 \%$ in start-up lost times.

Knoblaugh et al. [9] found that pedestrians increased their walking speed during inclement weather. Young pedestrians increased the walking speed by $9 \%$ from 4.82 fps to 5.24 fps while older pedestrians increased by $8 \%$ from 4.03 to $4.37 \mathrm{fps}$. In spite of increase in pedestrian speed, the crossing time of pedestrian should used for pedestrian signal not be changed to provide an excess time over the required to be on the conservative side.

Traffic volumes can also change due to inclement weather, necessitating the implementation of weather based timing plan. Maki [7] observed $15-20 \%$ reduction in volumes during off-peak hours and $15-30 \%$ during peak hour.

The change in the traffic flow parameter and traffic volumes necessitates implementation of optimized timing plans adapted to the ambient weather conditions. Bernardin, Lochmueller and Associates [5] reported a 23\% decrease in delay if inclement weather timing plans were implemented. Agbolosu-Amison et al. [10] estimated that retiming the signal for inclement weather can lead to $36 \%$ reduction in control delay for a 2 -hour snow and $18 \%$ reduction for a 1 hour snow event.

\section{Table 1 Comparison of Saturation Flow* Reduction}

\begin{tabular}{ccccc}
\hline $\begin{array}{l}\text { Weather } \\
\text { Condition }\end{array}$ & $\begin{array}{l}\text { Salt } \\
\text { Lake } \\
\text { City, UT }\end{array}$ & $\begin{array}{l}\text { Fairbanks, } \\
\text { AK }\end{array}$ & $\begin{array}{l}\text { Anchorage, } \\
\text { AK }\end{array}$ & $\begin{array}{l}\text { Minneapolis, } \\
\text { MN }\end{array}$ \\
\hline Normal & $1,808^{*}$ & 1,792 & 1,816 & 1,800 \\
Inclement & 1,432 & 1,538 & 1,600 & 1,600 \\
\hline Reduction & $21 \%$ & $14 \%$ & $12 \%$ & $11 \%$ \\
\hline * values in vehicles per hour \\
Optimized timing plans for inclement weather conditions \\
can be easily developed using weather-dependent traffic
\end{tabular}


flow parameters. Timing plan optimization software such as SYNCHRO [11], TRANSYT 7-F [12], PASSER [13] can be used for this purpose.

\section{DETECTION OF INCLEMENT WEATHER}

Despite the benefits associated with the implementation of special timing plans for inclement weather, there are very few instances of it in practice. The major problem faced for wide-scale implementation of weather-based timing plans is the nonexistence of accurate weather detection system that can be economically installed.

Remote Weather Information Systems (RWIS), which collect weather data for a large area, cannot be used for estimating the conditions at a particular intersection. This is because snow falls at a relatively wide range of temperatures, and relative humidity and barometric pressure can vary between storms. The magnitude of a storm can also vary across each intersection covered by RWIS. Maki [7] reported that RWIS data cannot be correlated with the actual conditions on the road and suggested the most effective way of implementing a weather-based timing plan is by using field personnel. Use of field personnel is a costly alternative and sometimes infeasible depending on the location of the signalized intersection. For wide-scale applicability, a local detector is needed which can automatically detect adverse weather conditions and implement appropriate timing plans.

Video image vehicle detection systems (VIVDS) have emerged as an alternative vehicle detection device. VIVDS automatically analyzes and extracts traffic information from images of the detection zones. It typically consists of video cameras, microprocessor-based equipment for processing the image, and software for interpreting the images and extracting the traffic data [14].

VIVDS measure differences between successive video image frames. The vehicle passage is determined using the variation caused by the vehicles in the gray levels of the black-and-white pixel groups. Variations due to non-vehicle factors, such as weather and shadows, are programmed to be excluded. Figure 2 shows the conceptual image processing algorithm currently for VIVDS [15]. Details regarding the video processing algorithm can be found elsewhere [16].

The VIVDS systems described above detect vehicles using image processing and send the actuation to the traffic controller to make appropriate decisions. The same system can be used for snow detection. The benefits of using VIVDS for snow detection are:

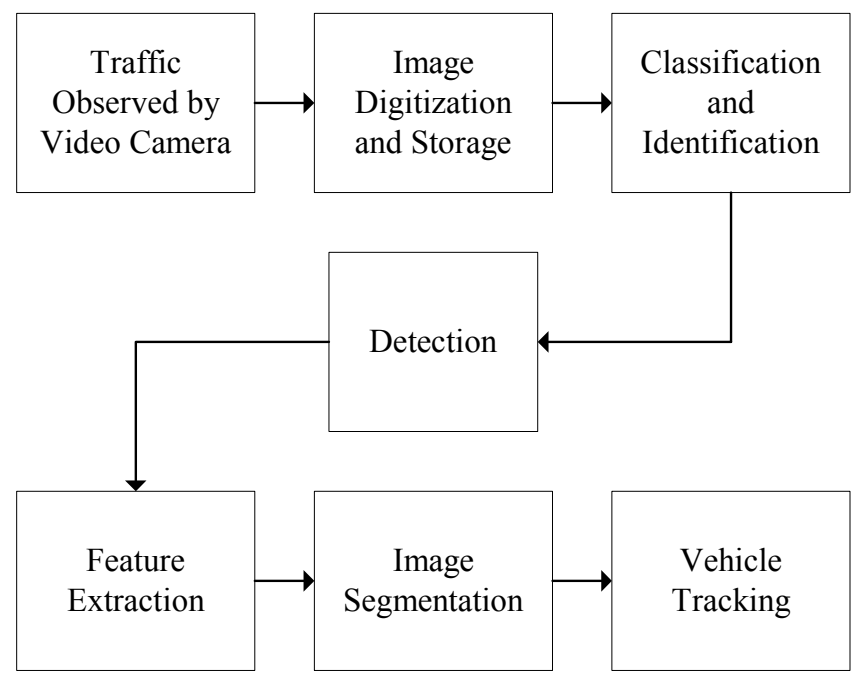

Figure 2 Conceptual image processing algorithm used by VIVDS

1. VIVDS systems can be deployed locally at each intersection and thus can be used for locally detecting the weather conditions and reporting it to the traffic controller.

2. They are non-intrusive detection system. So, they are not affected by the roadway conditions during snow storms.

3. The approach is economically feasible as the VIVDS employed for vehicle detection system can be used for weather detection by just upgrading the image detection software provided by the vendor.

Our proposed traffic controller logic is shown in Figure 3.

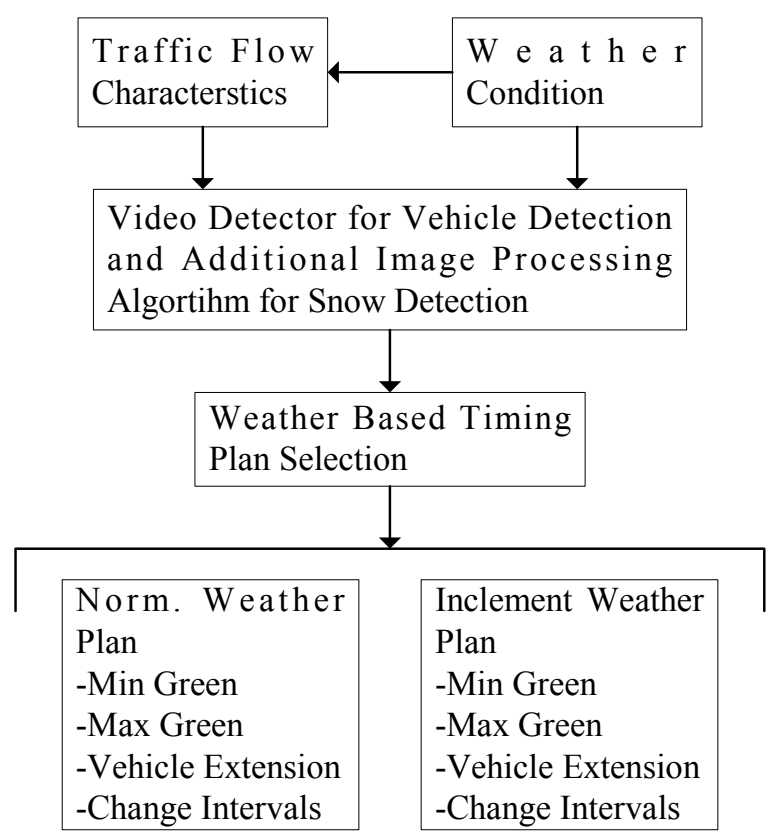

Figure 3 Proposed traffic controller logic 
In this approach the controller would use VIVDS for estimating traffic flow and implementing a timing plan. Under the proposed controller logic, VIVDS would detect both the traffic flow and snow conditions to choose a weather-based timing plan. The methodology used for image processing for snow detection is described hereafter.

\section{DETECTION OF INCLEMENT WEATHER}

Figure 4 lists the steps of our proposed image processing algorithm for snow detection. The step-by-step description of this algorithm is given below and follows the flow chart shown in Figure 4 (from top to bottom):

1. The colored (RGB) image (ImFrame) obtained from the VIVDS video is sent as an input to the algorithm at every 30 -sec interval. The other input to the algorithm is a reference image (RefFrame) (which is the snapshot view from the video on a normal day). The algorithm also uses the boundary of a snow detection region as an input.

The difference between the snow detection region in the current image and the reference image is obtained (ImDiff).

RGB Image Frame (ImFrame) is obtained from VIVIDS at every $30 \mathrm{sec}$

Image diffence (ImDiff) for the snow detection region is obtained by substracting image of the snow detection region in ImFrame from the same region in reference image (RefFrame)

Enhanced Image Differnce (EnhDiff) is found by adding RGB components of ImDiff.

EnhDiff is converted to binary image (BwEnhDiff)
by converting any difference below 125 to 0 and
any difference above it to be 1.

Figure 4 Image processing algorithm for snow detection
2. The RGB components of the image difference are added for amplification of the differences (EnhDiff).

3. The EnhDiff image is converted to binary image by applying threshold of 125 . Any value of greater than 125 is converted to 1 and values below it are converted to 1 (BwEnhDiff). The areas of snow region are so chosen that on a normal day they are dark and have a RGB value usually less than $[125,125,125]$. These regions when covered with white snow would have a RGB value of $[255,255,255]$.

4. The connected white areas (with a value 1) in BwEnhDiff having size greater than 10 pixels are obtained and summed. The threshold of 10 is used to eliminate noise of scattered white spots. This summation of connected white region (recognized to be snow covered area) is defined as Snow Area Index.

5. A moving average of Snow Area Index is taken over time to further reduce random noise. Moving average so obtained can be used for identifying the area on road covered with snow. Threshold on the average Snow Area Index can be used to switch from normal timing plan to inclement weather timing plan. This threshold value will depend on the size of snow detection region.

This detection algorithm was coded in MATLAB [17].

The Snow detection region is defined in the VIVDS for efficient operation of the algorithm. These regions should be inherently dark and should not be greatly affected by traffic movements. These regions should not have excessive sun glare, and should be well lighted at night. Medians and pave shoulders are examples of possible regions. These regions are usually lit by signal lights or street lights, and hence can also be used at night. They do not give much sun glare and are not influenced by traffic movements. Figure 5 provides an example location of snow detection regions.

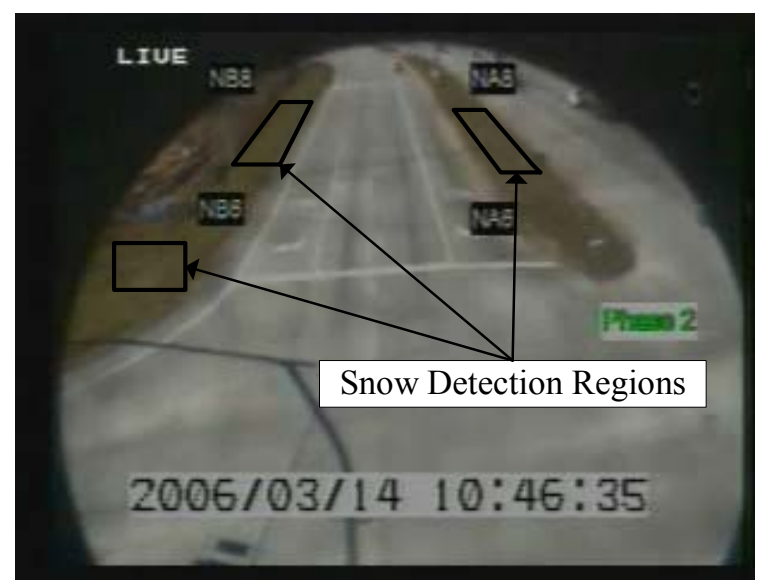

Figure 5 Location of Snow detection region 


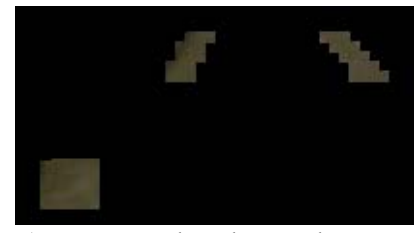

a) Normal day detector image received from Video

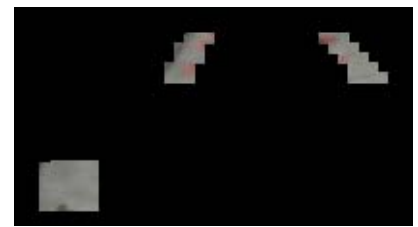

c) Snowy day detector image received from Video

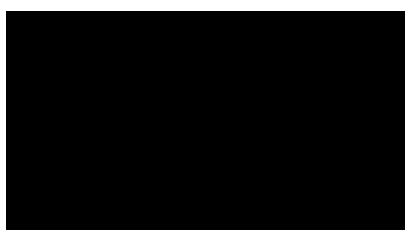

b) Processed normal day detector image $($ SnowAreaIndex $=0)$

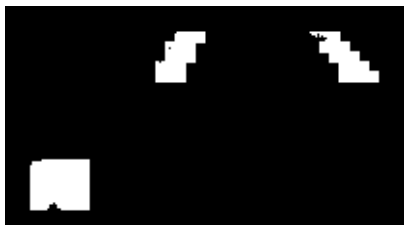

d) Processed snowy day detector image (SnowAreaIndex $=1637$ )

Figure 6 Example results given by snow detection algorithm.

Figure 6 shows the difference obtained from snow detection algorithm for normal day and snowy conditions using the proposed algorithm. Figure $6 \mathrm{a}$ and Figure $6 \mathrm{~b}$ show the normal day image received from video and processed image after applying the snow detection algorithm, respectively. A snow area index of 0 was obtained for this image. Figure $6 \mathrm{c}$ and Figure $6 \mathrm{~d}$ present a snowy day image and processed image. A higher snow area index of 1637 was obtained as expected. It should be noted that the threshold of snow area index for predicting snow would be depend on the total area of snow detection regions.

\section{TECHNIQUE VALIDATION}

Data from the signalized intersection of SR32 and SR38 at Noblesville, IN was used for validation of the proposed algorithm. Three hours of data was collected during a course of two days. Normal day data was collected on $14^{\text {th }}$ March, 2006 from 10:45 AM to 11:45 AM. Zero precipitation was reported by the closest weather station for this day [18]. Data was collected for a snowy day on $21^{\text {st }}$ March, 2006 from 7AM to 9AM. The weather station reported a 0.18 inch snow fall for the day.

The video obtained for both the days was processed through the snow detection algorithm. Figure 7 presents the results obtained for the two conditions. Figure 7 a shows the distribution of Snow Area Index over time of day. It can be seen as the snow accumulates on the detection region there is an increase in the snow area index. The Snow Area Index reaches a high value of 1500 2000. Figure $7 \mathrm{~b}$ presents the snow area index obtained for normal condition using the same snow detection region. The graph shows the snow area index remains very close to zero. Only slight noise variations are observed over a one hour period. Hence, the

snow detection algorithm can be successfully used for the detection of inclement weather.

\section{CONCLUSION AND DISCUSSION}

This paper proposed and validated a snow detection algorithm that can be effectively used to monitor snow conditions at a signalized intersection. The algorithm can be implemented at a very low cost and requires no hardware installation at the sites which use VIVDS for traffic detection.

The efficiency of the algorithm depends on the choice of the snow detection region. Regions having low sun glare and snow accumulation similar to the roadway are ideal for snow detection region. Grass median and curbs can be used in this context. Care should be taken that such regions should be marked on the roadway and should not be used for snow disposal. Any extra snow in these marked regions should also be removed when snow is being removed from the roadway.

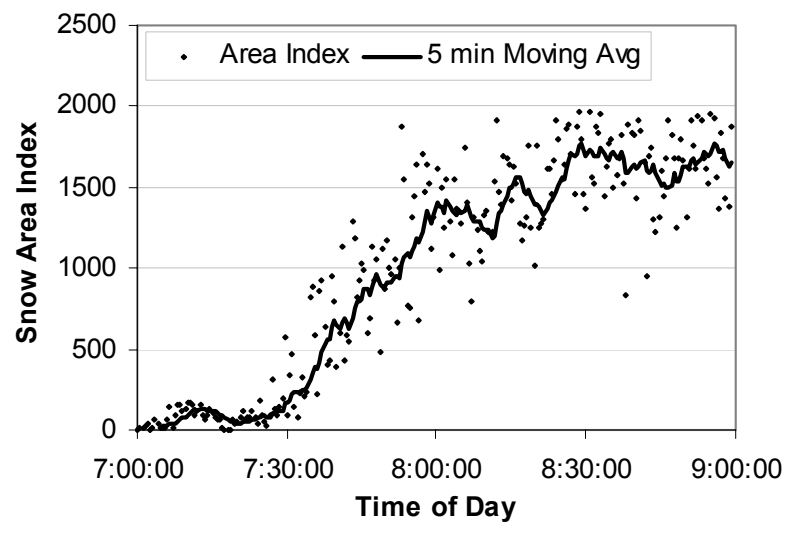

a) Two hour analysis on a snowy day (03/21/06) at Noblesville, IN

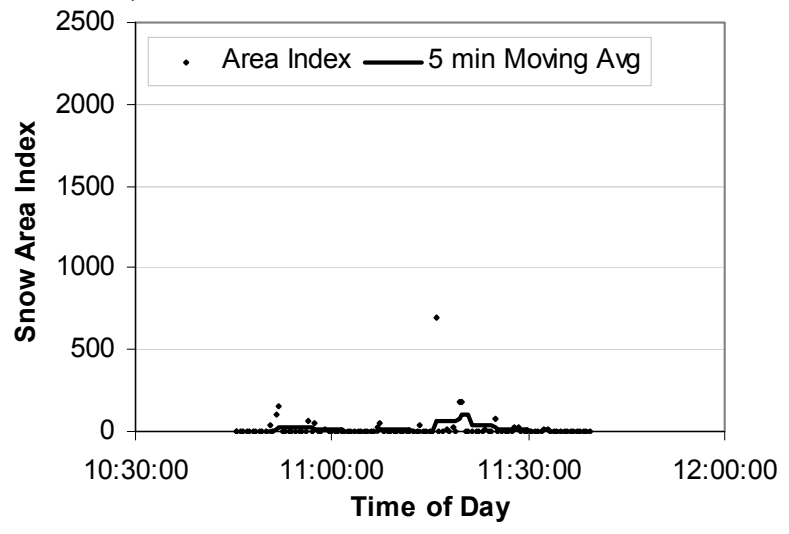

b) One hour analysis on a normal day (03/14/06) at Noblesville, IN.

Figure 7 Comparison of results obtained for snowy day versus normal day. 


\section{REFERENCES}

[1] Highway Capacity Manual, TRB, National Research Council, Washington D.C., 2000.

[2] Advanced Signal Controller ASC/3 Programming Manual, Econolite Control Products Inc., Anaheim, 2005

[3] H.J. Perrin, P.T. Martin, and B.J. Hansen, "Modifying Signal Timing During Inclement Weather," Transportation Research Record \#1748, TRB, National Research Council, Washington D.C., pp. 66-71, 2001.

[4] J.L. Botha and T.R. Kruse, "Flow Rates at Signalized Intersections under Cold Weather Conditions," Journal of Transportation Engineering, pp. 439-450, 1992.

[5] Bernardin Lochmueller and Associates,Inc, “ Anchorage Signal Upgrade -Final Report," 1995.

[6] FHWA Report, "Economic Impact of the Highway Snow and Ice Control," Final Report, FHWA-RD-77-95, Federal Highway Administration, Washington, DC, 1977.

[7] P.J. Maki, "Adverse Weather Traffic Signal Timing," Institute for Transportation Engineers 1999 Annual Meeting and Exhibit Compendium of Papers, Las Vegas, NV, August 1999.

[8] A.T. Ibrahim, and F.L. Hall, "Effect of Adverse Weather Conditions on Speed-Flow-Occupancy Relationships," Transportation Research Record \# 1457, Transportation Research Board, National Research Council, Washington, DC, pp. 184-191, 1994.

[9] I.L.L Knoblauch, M.T. Pietrucha, and M. Nitzburg, "Field Studies of Pedestrian Walking Speed and Start-Up Time," Transportation Research Record \# 1538, Transportation Research Board, National Research Council, Washington, DC, pp. 27-38, 1996.

[10] S.J. Agbolosu-Amison, A.W. Sadek, and B. Henry, "Factors Affecting Benefits of Implementing Special Signal Timing Plans for Inclement Weather Conditions," Transportation Research Record \# 1925, Transportation Research Board, National Research Council, Washington, DC, pp. 146-155, 2005.

[11] Trafficware Corporation, SYNCHRO 5.0 Traffic Signal Timing Software User Guide, Albany, CA, 2000.

[12] Transportation Research Center, Transyt-7F User's Guide, University of Florida. Gainesville, 1998.
[13]C.P. Chang, and C.J. Messer, “ Arterial Signal Timing Optimization Using PASSER II-90 - Program Users Manual," Texas Transportation Institute, Report 467-2F, 1991.

[14]E. Luz, Y. Mimbela and L.A. Klein, "A Summary of Vehicle Detection and Surveillance Technologies used in Intelligent Transportation Systems," The Vehicle Detector Clearinghouse, New Mexico State University, Fall 2000.

[15]L.A. Klein, Sensor Technologies and Data Requirements for ITS, Norwood, MA: Artech House, 2001.

[16]C.A. MacCarley, S. Hockaday, D. Need, and S. Taff, "Evaluation of Video Image Processing Systems for Traffic Detection," Transportation Research Record \#1360, Transportation Research Board, National Research Council, Washington, DC, 1992.

[17]MATLAB 6.5., The Mathworks. Inc., Natick, Massachusetts, 2003.

[18] Website URL:

http://www.wunderground.com/history/airport/KEYE/2006/ 3/14/DailyHistory.html?req city=NA\&req state=NA\&req statename $=\mathrm{NA}$. 